\title{
COMPARATIVE STUDY OF AODV, R-AODV \& PHR-AODV IN MANET
}

\author{
Sarita Soni ${ }^{1}$, Samir Srivastava ${ }^{2}$ \\ ${ }^{1}$ Computer Science \& Engineering, KNIT Sultanpur, India \\ saritasoni90@gmail.com \\ ${ }^{2}$ Computer Science \& Engineering, KNIT Sultanpur, India \\ samir@knit.ac.in
}

\begin{abstract}
Mobile ad-hoc network formed by wireless hosts which may be mobile. Ad-hoc network without using apre-existing infrastructure. Routes between nodes may potentially contain multiple hops. In MANET nodes are free to move randomly and organize themselves arbitrarily, thus the network's wireless topology may change rapidly unpredictably. Due to movement of nodes, QOS(Quality of Service)routing is difficult task in MANET. In this paper from the QOS, we differentiating traffic and services, QOS Provide a higher network PDR, maximum bandwidth, low delay, reduce control-overhead. In this paper we decrease the congestion and path failure during packet forward. Here multipath routes so packet goes to various path then hackers and unauthorized person does not get the packet and routes. By the QOS we increase the PDR and end to end delay, control overhead.
\end{abstract}

Keywords: QOS (Quality of Service), AODV and R-AODV, PHR-AODV.

\section{INTRODUCTION}

MANET is the collection of mobile nodes that make network for information exchange. MANET is free from infrastructure and central authority and transfer message through hop by hop technique. AODV is the reactive routing protocol, when source need to send data then source node initiate route discovery process and established route to destination node on demand. AODV is the single path routing protocol where R-AODV and PHR-AODV is the multipath routing protocol. AODV is the single path routing protocol that increased latency and packet loss due to dynamic nature of mobile node and routing environment. The performance of AODV is decreased due to loss of unicast route reply packet. To overcome this problem RAODV routing protocol is used. R-AODV supports multiple route reply packet and increased the performance. To increased the security and increased the throughput PHRAODV routing protocol is used.

\section{OVERVIEW OF ROUTING PROTOCOL}

\subsection{AD-HOC on Demand Distance Vector (AODV)}

AODV routing protocol is initiated by destination node and its works on sequence number concept and provide loop free routing. AODV have works on two phase i) Route Discovery ii) Route Maintenance.

In route discovery process when source node want to send data to destination node then source node send RREQ packet to their neighbor nodes and these neighbor nodes forward RREQ packet to their neighbor node until it reach to destination node. When intermediate nodes receive
RREQ packet then intermediate node set reverse path to previous node. When the first RREQ packet reach to destination node then destination node send unicast RREP packet to source node. These RREP packets travel through the reverse path set by intermediate node.

If any link break or any node move out from network then there is possibility of packet drop. When node detect packet drop or link failure then that node send RERR packet to source node.

Intermediate node avoid RREQ packet by matching source IP address and RREQ ID of packet.

Algorithm Step:-

AODV ( S, D , Data , EED, Bandwidth ) // Route Discovery Phase

\{ Source $\mathrm{S}$ initiates the RREQ packet and search neighboring nodes in the direction of destination $\mathrm{D}$;

If ( next-hop!=D \&\& Loop free )

$\{$ Source $\mathrm{S}$ broadcast the RREQ packet to all the neighboring nodes and continues till destination is not explored. \}

else

\{Destination $\mathrm{D}$ is reached \}

In the cache of the direct/intermediate nodes retrieve the routes from route caches. Add these routes inthe route record and then generate the route reply packets in that order . // Route Reply Phase

If the route/s is/are found \{ Maintain a list of all discovered routes as LR. 
RA-AODV ( LR , EED, BW , Hop count ) ; \} // AODV provisioning Reliability Phase being called here else

$\{$ Destination node $\mathrm{D}$ not reachable may be due to high mobility of nodes and network partitioning; \}

\subsection{R-AODV (Reverse AODV)}

As Earlier In AODV, destination node send single route reply message to source node. So these route reply message can be missed due to high mobility and pre-calculated reverse path and due to this large number of retransmission and congestion in network take place.

To overcome these problems R-AODV routing protocol is used. It is the optimized version of AODV routing protocol. R-AODV support multiple route-reply (using discovery methodology) to avoid RREP packet loss and reduce network congestion and retransmission also.

In R-AODV Route discovery process from source to destination is same as AODV and packet format of RREQ is also same as AODV packet format. When packet reach to destination node, then destination node create reverse route request (R-RREQ) packet and broadcasted to its neighbor node. Packet format of R-RREQ is given in Table 1

Table 1.1 R-RREQ Packet Format

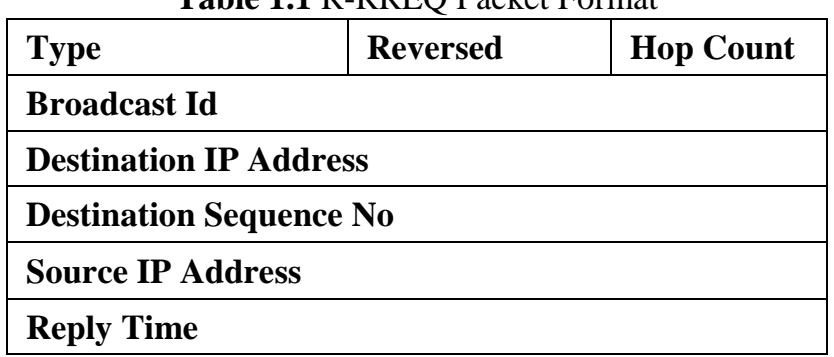

When the source node received first R-RREQ packet then it start packet transmission immediately and store the other late R-RREQ packet for future use. When node received RRREQ packet and it is not a source node then that node create forward route entry and broadcast R-RREQ packet to its neighbor node within their transmission range.

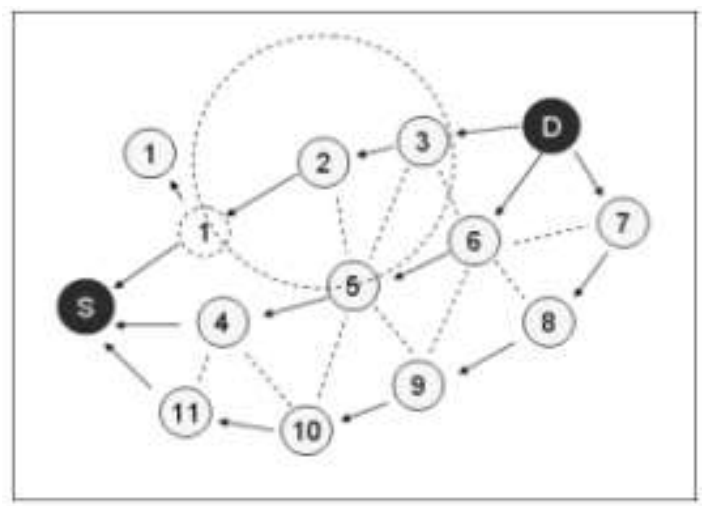

Fig 1.R-RREQ from source to destination node
In the figure, Node D broadcast the R-RREQ packet to their neighbor node in order to find the source node. According to figure the source node receive three path (i) D- 3- 2- 1- S, (ii) D- 6-5-4-S, (iii) D-7-8-9-10-11- S. Suppose source node received first R-RREQ from path (i) then source node start transmission using path (i) and store other path for future use. During transmission node 1 move out from transmission range of source node then source node start transmission using path (ii) instead of restarting of route discovery process(like AODV).

\subsection{Path-Hoping based Routing Protocol}

PHR is the on demand routing protocol, and it is extension of R-AODV routing protocol. PHR-AODV does not contain permanent route in node routing table. PHR- AODV routing table prevents from data loss by malicious node and helps in uniform load distribution among the nodes.

Routing of RREQ and R-RREQ packets of PHR-AODV is same as R-AODV and their packet formats are also same as $\mathrm{R}-\mathrm{AODV}$ routing protocol.

In the route discovery process source node start reverseroute discovery procedure and broadcast RREQ packets to their neighbor node. These RREQ packets contain information like source node address, destination node address, message type, broadcast id, hop count, source sequence number, destination sequence number and request time.

When neighbor node receives RREQ packets then neighbor node forward these packets to their neighbor node until its reach to destination node like AODV does.

When destination node receive first RREQ message then destination node create R-RREQ packets and flood R-RREQ packet to find source node. R-RREQ packets contain some information like reply source-id, reply-destination-id, reply broadcast-id, hop count, destination sequence number and reply-time. When source node receives R-RREQ packets from its neighbor node then source node simply build partial node disjoint path.After receiving all nodes disjoint path within the timeout period, source node arrange them in ascending order of their hop count value. Now source node start data transmission on these store paths in random manner, we consider FCFS here. When any paths fail or break then source node delete that path from source routing table and continue data transmission from remaining path lists.

When source node's path list is empty then Source node reinitiate route discovery process. 


\subsubsection{Path-Hoping Effect on Routing Load and}

\section{Security}

Traffic load and security are serious problem of any routing protocol. PHR-AODV routing protocol try to solve these routing problems. In the below figure there are three path from source node to destination node. (1). S->1->2->3->D, (2).S-> 4->5->D, (3).S->6->D.

Now path 1 have hop count value 3, path 2 have hop count value 2 and path 3 have hop count value 1 . So when source node arrange them in ascending order of their hop count value thenpath 3 top in the path list and path 1 last in the path list of source node. Source node send first data packet through path 3 then send second packet through path 2 and third packet through path 1 and fourth packet through path 3 and so on. This approach increase router lives.

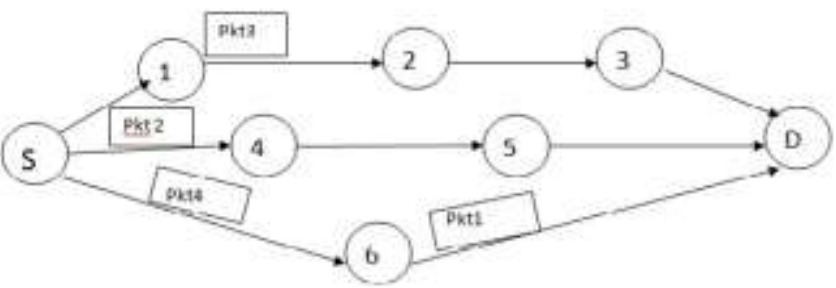

Fig.2 PHR-AODV Routing Protocol

Let assumed path 2 have a malicious node in the above figure then there is $100 \%$ data loss in AODV routing protocol. But in case of PHR-AODV routing protocol there are three routing path and one path contain malicious node then data loss $=(1 / 3) * 100=33 \%$,So we can say that only $33 \%$ data loss occurred.

PHR-AODV give analytical and effective method to estimate the security of network. Probability of active malicious node

$$
\mathrm{Pm}=(\mathrm{Nrp} * \mathrm{Nm}) / \text { Ntotal }
$$

Where Nrp is number of node in routing path, Nm is number of malicious node and Ntotal is number of total node in the network. $\mathrm{Np}$ is the number of path from source to destination. The malicious node intrusion rate is

$$
\mathrm{Pi}=\mathrm{Pm} . / \mathrm{Np}
$$

\section{SIMULATION AND PERFORMANCE}

\section{EVALUATION}

In this section we describe the simulation modal and analysis their performance using performance metrics. We use NS2 for simulation and consider some performance metrics like PDR, END TO END DELAY and CONTROL OVERHEAD and compare with other two (AODV, RAODV) routing protocol .

\begin{tabular}{|l|l|}
\hline Simulation Time & $100 \mathrm{Sec}$ \\
\hline Routing protocols & AODV, R-AODV,PHR-AODV \\
\hline Area of Terrain & $150{ }^{*} 1500$ \\
\hline Number of nodes & $20,30,40,50,60$ \\
\hline Type of Traffic & TCP,UDP \\
\hline Size of Packet & 512 byte \\
\hline MAC Type & IEEE 802.11 \\
\hline $\begin{array}{l}\text { Transmission } \\
\text { Range }\end{array}$ & 250 meter \\
\hline Transmission rate & 4 Packet/Sec \\
\hline Antenna Type & Omni Antenna \\
\hline Propagation Type & Two Ray Ground \\
\hline Queue Type & Queue/DropTail/PriQueue \\
\hline Queue Length & 50 \\
\hline Mobility Model & Random way Point \\
\hline
\end{tabular}

Fig 3: Simulation Parameter

\section{RESULT AND DISCUSSION}

PDR (Packet Delivery Ratio)

Aggregate PDR Vs Routing Protocol

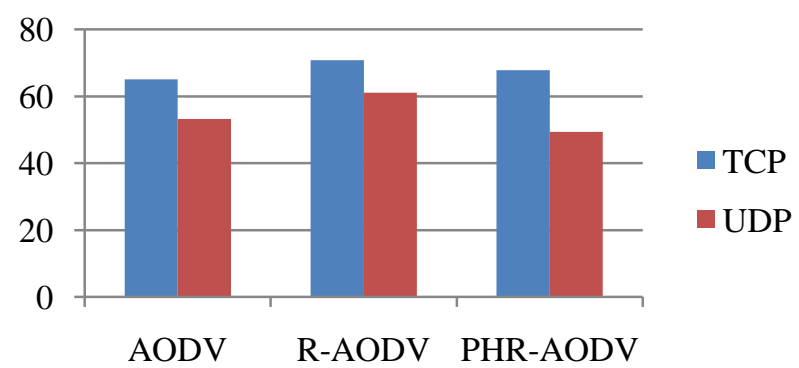

End To End Delay

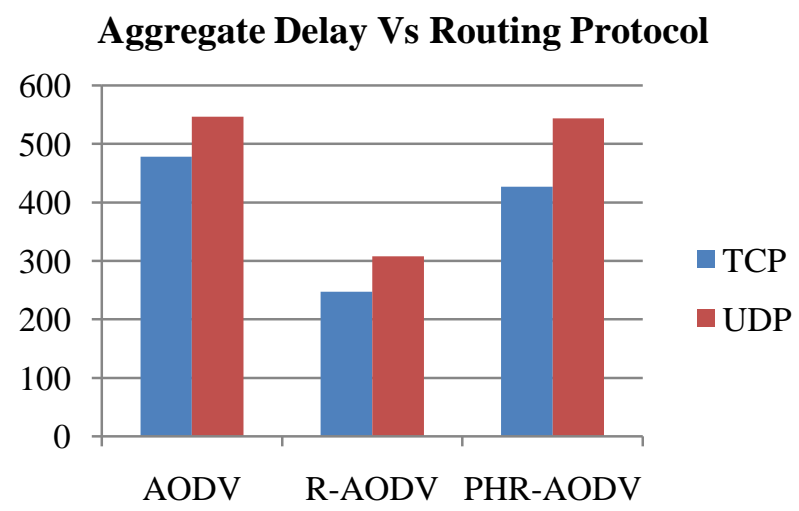

Control Overhead 


\section{Aggregate Control Overhead Vs Routing Protocol}

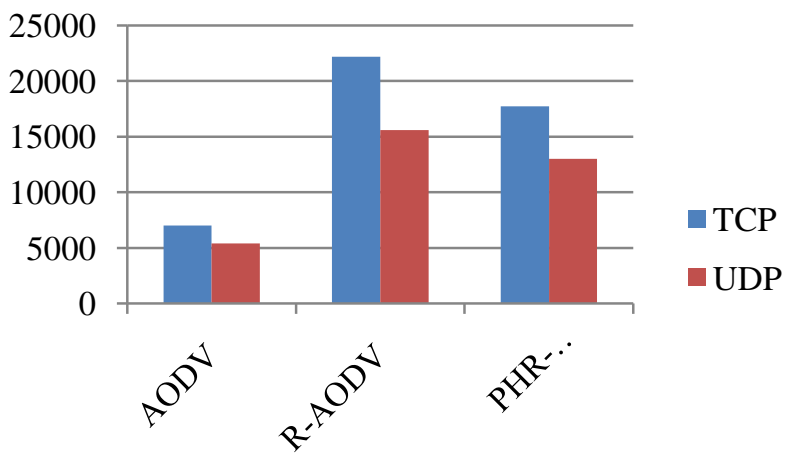

In terms of PDR (Packet Delivery Ratio), R-AODV with TCP connection perform better than AODV and PHRAODV.

In terms of End to End Delay, R-AODV with TCP connection have less delay than AODV and PHR-AODV.

In terms of Control Overhead, AODV with UDP connection have less overhead than R-AODV and PHR-AODV with TCP and UDP connection.

Table 2 Comparison of routing table

\begin{tabular}{|l|l|l|l|}
\hline & AODV & $\begin{array}{l}\text { R- } \\
\text { AODV }\end{array}$ & $\begin{array}{l}\text { PHR- } \\
\text { AODV }\end{array}$ \\
\hline PDR & LOW & HIGH & MEDIUM \\
\hline DELAY & HIGH & LOW & MEDIUM \\
\hline $\begin{array}{l}\text { CONTROL } \\
\text { OVERHEAD }\end{array}$ & LOW & HIGH & MEDIUM \\
\hline
\end{tabular}

\section{CONCLUSION}

In this paper we analysis the performance of AODV, RAODV and PHR-AODV on the basis of PDR,DELAY and CONTROL OVERHEAD. In terms of PDR and CONTROL OVRHEAD, R-AODV give better performance than AODV and PHR-AODV. While in terms of DELAY, AODV performance is better than R-AODV and PHR-AODV.

\section{FUTURE SCOPE}

In future we will add other algorithm for detection and prevention of malicious node. We can also modified PHRAODV for better packet delivery ratio and low control packet overhead.

\section{REFERENCES}

[1]. C.E. Perkins and E. M. Royer, "Ad hoc on-demand distance vector routing" in Proc. WMCSA, New Orleans, LA, pp. 90-100, Feb. 1999.

[2]. Elizabeth M. Royer and Chai-KeongToh, "A Review of Current Routing Protocols for Ad Hoc Mobile Wireless
Networks," IEEE Personal Communications, Vol. 6, No. 2, pp. 46-55, April 1999.

[3]. M. K. Marina and S. R. Das “On-Demand Multi Path Distance Vector Routing in Ad Hoc

Networks" in Proc. ICNP 2001, pp. 14-23, Nov. 2001.

[4]. A. Nasipuri and S. R. Das, "On-Demand Multipath Routing for Mobile Ad Hoc Networks" Proc. ICCN 1999, pp. 64-70, Oct. 1999.

[5]. Tarique, M., Tepe, E., SasanAdibi, and Shervin Erfani, "Survey of multipath routing protocols for Mobile Ad-hoc networks", Journal of Network and Computer Applications, 32:1125-1143, 2009.

[6]. Chonggun Kim, ElmurodTalipov and ByoungchulAhn, "A Reverse AODV Routing Protocol in Ad Hoc Mobile Networks," LNCS 4097, pp. 522-531, 2006.

[7]. Stavroulopoulos, T. Antonakopoulos and V. Makios, 2001. "Performance evaluation of mobile ad hoc network routing protocols for real time applications support," in Proceedings of COMCON ' 8 , Crete, Greece.

[8]. Divecha, B., A. Abraham, C. Grosan and S. Sanyal, 2007. Impact of node mobility on MANET routing protocols models. Presented at JDIM, pp: 19-23.

[9]. Azad, S., A. Rahman and F. Anwar, 2007. A performance comparison of proactive and reactive routing protocols of mobile ad-hoc network (manet). Journal of Engineering and Applied Sci., 2(5): 891-896.

[10]. The CMU Monarch Project, "Wireless and Mobility Extensions to ns-2", www.monarch.cs.cmu.edu/cmuns.html. [11]. Robin Singh and Praveen Tripathi," A Survey on TCP (Transmission Control Protocol) and UDP (User Datagram Protocol) over AODV Routing Protocol" in IJR Vol-1, Issue-7, August 2014 ISSN 2348-6848.

[12]. C. Perkins, E. Belding-Royer Ad hoc on-Demand Distance Vector (AODV) Routing, RFC

3561, July 2003

[13]. Chonggun Kim, ElmurodTalipov, and ByoungchulAhn, "A Reverse AODV Routing Protocol in Ad Hoc Mobile Networks" , LNCS 4097, pp. 522 - 531, 2006.

[14]. C. K.-L. Lee, X.-H.Lin, and Y.-K. Kwok, “A Multipath Ad Hoc Routing Approach to

Combat Wireless Link Insecurity," Proc. ICC 2003, vol. 1, pp. 448-452, May 2003.

[15]. S.-J. Lee and M. Gerla, "Split Multipath Routing with Maximally Disjoint Paths in Ad Hoc

Networks," Proc. ICC 2001, vol. 10, pp. 3201-3205, June 2001.

[16]. M. K. Marina and S. R. Das "On-Demand Multi Path Distance Vector Routing in Ad Hoc

Networks," Proc. ICNP 2001, pp. 14- 23, Nov. 2001.

[17]. NS, The UCB/LBNL/VINT Network Simulator (NS), http://www.isi.edu/nsnam/ns/, 2004.

[18]. Zhi Li and Yu-Kwong Kwok, "A New Multipath Routing Approach to Enhancing TCP

Security in Ad Hoc Wireless Networks" in Proc. ICPPW 2005.

[19]. Chonggun Kim, ElmurodTalipov, and ByoungchulAhn, "A Reverse AODV Routing Protocol in Ad Hoc Mobile Networks", LNCS 4097, pp. 522 - 531, 2006. 
[20]. HumairaNishat, Vamsi Krishna K, D.SrinivasaRao and Shakeel Ahmed, "Performance Evaluation ofOn-Demand Routing Protocols AODV and Modified AODV (R-AODV) in MANETS," InternationalJournal of Distributed and Parallel Systems, vol. 2, no. 1, January 2011.

[21]. M. K. Marina and S. R. Das "On-Demand Multi Path Distance Vector Routing in Ad HocNetworks," Proc. ICNP 2001, pp. 14-23, Nov. 2001.

[22]. Pravanjan Das and Upena D Dalal, "A Comparative Analysis of AODV and R-AODV Routing Protocols in MANETS", International Journal of Computer Applications 72(21):1-5, June 2013.

[23]. Mehdi Zarei, KarimFaez and JavadMoosaviNya, "Modified Reverse AODV Routing Algorithm using Route Stability in Mobile Ad Hoc Networks" Proceedings of the 12th IEEE International Multitopic Conference, December 23-24, 2008. 